\title{
MEDIAÇÃO CULTURAL EM BIBLIOTECAS PÚBLICAS DE CURITIBA
}

\section{CULTURAL MEDIATION IN CURITIBA PUBLIC LIBRARIES}

\author{
Josiele Scheuera \\ Jéssica Bedin ${ }^{b}$ \\ Priscila Machado Borges Sena ${ }^{\circ}$
}

\begin{abstract}
RESUMO
Introdução: Ao considerar fundamental a atuação das bibliotecas públicas na função de colaborar com a difusão e a visibilidade das diversas manifestações culturais e a sua contribuição na disseminação e consolidação do conhecimento, a pesquisa apresentada traz uma análise da situação atual das bibliotecas públicas e seus profissionais na cidade de Curitiba. Objetivo: Com vistas a descrever práticas culturais e conhecer a dinâmica das bibliotecas públicas de Curitiba. Metodologia: Para tal, realizou-se pesquisa exploratória, bibliográfica, descritiva e abordagem qualitativa. Resultados: Obteve-se a identificação e descrição de 28 projetos que podem ser caracterizados como práticas culturais. Conclusões: Evidencia-se que bibliotecárias e bibliotecários podem auxiliar no desenvolvimento da comunidade e a mediação cultural pode gerar inclusão, apropriação da informação, desenvolver estímulos para novas áreas de conhecimento, promover lazer, entretenimento e acesso à cultura.
\end{abstract}

Descritores: Mediação cultural. Biblioteca pública. Bibliotecário. Biblioteconomia.

\section{INTRODUÇÃo}

Tendo por fundamental a atuação das bibliotecas públicas na função de colaborar com a difusão e a visibilidade das diversas manifestações culturais e a sua contribuição na disseminação e consolidação do conhecimento, a pesquisa apresentada nesse artigo traz uma análise da situação atual das

a Graduada em Biblioteconomia pela Universidade Comunitária da Região de Chapecó (UNOCHAPECÓ). E-mail: josiele@alunos.utfpr.edu.br

b Doutoranda no Programa de Pós-Graduação em Ciência da Informação na Universidade Federal de Santa Catarina (UFSC). Docente do curso de Biblioteconomia EaD da Universidade Comunitária da Região de Chapecó (UNOCHAPECÓ). E-mail: jessicabedin@unochapeco.edu.br

c Doutora em Ciência Informação pela Universidade Federal de Santa Catarina (UFSC). E-mail: priscilasena.pesquisa@gmail.com 
bibliotecas públicas e seus profissionais na cidade de Curitiba.

Torna-se relevante considerar a escassez de recursos financeiros, o constante avanço das inovações tecnologias e muitas vezes a falta de estímulo do próprio profissional da Biblioteconomia para que a biblioteca pública se torne um lugar atrativo para a sociedade. Por isso, a questão que norteou a pesquisa indagou quais medidas e práticas culturais as bibliotecas públicas de Curitiba oferecem para se tornarem lugares de construção de sentido e conhecimento.

Desse modo, com o estudo teve-se o objetivo de descrever práticas culturais a fim de conhecer a dinâmica das bibliotecas públicas de Curitiba, bem como verificar se estas apresentavam-se conforme Brayner (2018), como equipamento cultural moderno, comprometido em formar cidadãos úteis por meio de práticas docilizadoras de seus corpos.

Justifica-se este estudo pela necessidade de levar aos profissionais da Biblioteconomia um olhar mais atuante na sociedade para que não seja reproduzida a ideia que povoa uma grande maioria do imaginário do povo brasileiro que, como afirma Brayner (2018, p. 54) "as ações envolvidas no cotidiano de uma biblioteca são tão desprovidas de complexidade que qualquer zé-ninguém pode executá-las sem o menor atropelo".

O cenário atual exige que o bibliotecário se dispa da neutralidade técnica que provoca um distanciamento da sociedade. Sendo assim, é necessário promover o contato entre os sujeitos, criando canais de comunicação que permitam estimular sensações, sentidos e sentimentos, o que pode ocorrer pela linguagem da cultura (MARTINS; PICOSQUE, 2012).

Dessarte, na próxima seção apresenta-se uma reflexão sobre as bibliotecas públicas e a potencialidade do papel do profissional da Biblioteconomia.

\section{BIBLIOTECA PÚBLICA}

As bibliotecas públicas possuem grande potencial para estimular a autonomia nas pessoas, apesar de possuir algumas dificuldades de recursos, elas representam enorme capacidade educacional, informacional, cultural e de lazer. Por outro lado, a realidade das bibliotecas públicas brasileiras, no geral 
está muito distante do ideal para atingir o potencial que lhe pertence.

Com o pensamento do ideal de biblioteca pública, Costa (2016) apresenta uma bela descrição:

As bibliotecas públicas devem ser abertas, culturais, vivas, interativas, variadas, convidativas, motivadoras, inspiradoras, oferecer boas condições ambientais, e parece uma ideia contemporânea, mas vários autores citaram isso no século passado. Estes espaços devem trabalhar de forma integrada, as bibliotecas devem ser paiol de pensamentos lúdicos e críticos, não podemos mais pensar na biblioteca como uma vertente somente literária, ela deve ampliar suas atividades, ser um centro e instrumento principalmente de libertação para os seus utilizadores (COSTA, 2016, p. 27)

A profissão em Biblioteconomia enfrenta muitos desafios, no entanto, cabe aos profissionais que atuam nessa área fomentar ações culturais a fim de despertar o desejo e curiosidade pela leitura e busca de informação, para que, ao construir conhecimento, o sujeito interagente modifique a sua realidade.

Para Cunha (2002), a biblioteca pública tem o papel de ser a instituição capaz de contribuir para o contato e o cultivo de valores humanos, estimulando à convivência com outras culturas, levando conhecimento das raízes culturais, e o desenvolvimento de culturas locais.

Sendo assim, segundo Rastelli e Cavalcante (2014, p. 44)

[...] considera-se que as bibliotecas, como dispositivos produtores de sentidos, permitem o acesso à informação, observando a construção de significados vivenciados através da pesquisa, da leitura, da literatura em geral, dos eventos culturais e do contato com as artes.

A biblioteca pública é detentora do poder de promover o protagonismo das comunidades, valorizando a diversidade ela estimula a inclusão social e o desenvolvimento local (RASTELI; CAVALCANTE, 2014).

Nessa vertente, pode-se concordar com Silveira e Reis $(2008$, p. 3) ao expressar que:

É, portanto, função de qualquer biblioteca pública colaborar para a difusão e visibilidade da ampla gama das manifestações culturais humanas, sem se levar em consideração critérios ligados à etnia, crença religiosa, condição financeira, questões sexuais ou políticas; além de propiciar amplo acesso aos vários signos informacionais passiveis de serem preservados em um acervo, tendo-se em vista contribuir para a consolidação e disseminação do conhecimento. 
A biblioteca pública deve ser vista, perante as políticas públicas, como organismo de promoção e de apropriação de leitura, como ferramentas de desenvolvimento de cidadania. Pois, como afirmam Rasteli e Cavalcante (2014, p. 53) "quando a biblioteca pública valoriza o conhecimento local, promove o empoderamento, valorizando expressões individuais e coletivas, garantindo tanto a socialização quanto a produção de múltiplos conhecimentos e saberes".

Para que a biblioteca pública possa realizar a função de provedora do desenvolvimento de cidadania é importante salientar o papel da mediação cultural. É por meio da mediação cultural que se potencializa as estratégias de produção, comunicação e produção de conhecimentos (RASTELI; CAVALCANTE, 2014). Para que isso ocorra, torna-se necessário profissionais competentes para criar mecanismos de localização da informação em suas diferentes formas, além de tornar acessível informações relevantes que gerem reflexões e atuem na construção do indivíduo e na sua relação com a sociedade.

Na seção a seguir, apresenta-se a base conceitual de mediação cultural, a fim de demonstrar como profissionais da Biblioteconomia podem agir para que a biblioteca pública seja um espaço democrático, fomentador de conhecimento e lazer, ativo na comunidade em que está inserido.

\section{MEDIAÇÃO CULTURAL E A FORMAÇÃO DE CIDADÃO}

As ideias que percorrem o imaginário, não só brasileiro, mas também de outras populações, sobre a figura do profissional da Biblioteconomia é algo discutido ao longo da história. Em entrevista, Brayner tem a seguinte resposta sobre o perfil bibliotecário:

Pierce Butler, professor de Biblioteconomia da Universidade de Chicago, já denunciava a postura em 1933: "Ao contrário de seus colegas de outros campos de atividade social, 0 bibliotecário é estranhamente desinteressado aos aspectos teóricos de sua profissão. O bibliotecário é o único a permanecer na simplicidade de seu pragmatismo" (BRAYNER, 2018, p. 25).

Ao possuir características de um intelectual tradicional o bibliotecário limita-se ao mundo fechado das ideias e das palavras contidas dentro da biblioteca não percebendo que isto causa distanciamento (SANCHES; RIO, 2010). A partir dos primeiros anos do século XX este profissional deixa de ser 
encarado como um erudito que preserva incólume os segredos de um acervo, para tornar um facilitador do acesso à informação (SILVEIRA; REIS, 2008).

Nesse contexto, torna-se necessária uma nova postura do profissional diante as necessidades, que não são estanques, da sociedade. As demandas informacionais atuais exigem que as bibliotecas proponham inovações para continuar sendo uteis aos seus interagentes. Nessa vertente se torna essencial o exercício da mediação cultural. Segundo Rastelli e Cavalcante (2014, p. 44) "mediar informações solicita um olhar atento para a construção de acervos, organização dos espaços, frequência nas realizações das atividades culturais e práticas pedagógicas desenvolvidas nessas instâncias". Para Almeida (2012), as mediações são conexões que se estabelecem entre as ações sociais e as motivações individuais e coletivas.

Para que a mediação ocorra, é necessário tomar consciência de seu papel crítico, informador e revolucionário. A esse respeito Sanches e Rio (2010, p. 113) declaram:

Esse profissional, ao se posicionar como um agente canalizador de ações de interferência, propicia um espaço promotor da formação da autonomia do indivíduo. Criando espaços dentro da unidade de informação que potencializa no indivíduo clareza dos conceitos que atuaram e atuam como fatores condicionantes de sua personalidade sociocultural, o bibliotecário disponibiliza a sua comunidade usuária recursos cognitivos que permitam a revisão criteriosa dos princípios constituintes dos valores que orientam sua ação individual no social.

A mediação cultural oferece um amplo campo de possibilidades de atuação ao bibliotecário. O leque de atividades que podem ser desenvolvidas é inimaginável, dependerá das necessidades apontadas pela sociedade. Dantas (2008, p. 4) afirma "que as mediações seriam estratégias de comunicação em que, ao participar, o ser humano se representa a si próprio e o seu entorno, proporcionando uma significativa produção e troca de sentidos". Assim, a mediação cultural tem o poder de libertar o indivíduo de forma que ele se desenvolva, de fazê-lo dialogar com os seus semelhantes e fazer com que se reconheça como um indivíduo dentro da sociedade.

As bibliotecas públicas entrevistadas para a pesquisa possuem um amplo trabalho de mediação cultural, cada uma, de forma diferente, contribui com a sociedade oferecendo informação, lazer e interação social. Dessa forma, para a 
seleção e aproximação com as realidades almejadas, seguiu-se os procedimentos metodológicos descritos na próxima seção.

\section{PROCEDIMENTOS METODOLÓGICOS}

Essa investigação parte da pesquisa exploratória que, segundo Gil (2010), é desenvolvida com o objetivo de proporcionar uma visão geral de determinado fato. Logo, foi utilizada para proporcionar mais familiaridade com o assunto. A maioria dessas pesquisas envolve: levantamento bibliográfico; entrevistas com pessoas que tivessem experiências práticas com o problema pesquisado e análise de exemplos que estimulem a compreensão (GIL, 2008). Procedimentos utilizados aqui para o desenvolvimento da pesquisa.

Para o desenvolvimento do trabalho, também foi realizada uma pesquisa descritiva, com abordagem qualitativa e técnica de pesquisa bibliográfica.

Segundo Lopes (2006) a pesquisa descritiva estuda uma determinada população, descrevendo suas características e servem para proporcionar uma nova visão do problema. A pesquisa descritiva exige do investigador uma série de informações sobre o que deseja pesquisar. Esse tipo de estudo pretende descrever os fatos e os fenômenos de uma determinada realidade (TRIVIÑOS, 1987).

Também foi desenvolvida a pesquisa qualitativa de coleta de dados no formato de entrevista semiestruturada, tendo em vista, que as bibliotecas possuem características diferentes, as argumentações foram diferentes para cada caso para que pudessem abranger em maior totalidade as diferenças de cada biblioteca analisada. Como afirma Roesch (1999) a entrevista semiestruturada serve para entender os significados que as pessoas atribuem a determinados assuntos e Malhotra (2001) completa abordando que esse tipo de entrevista pode ser utilizado para descobrir crenças, atitudes e sensações sobre determinado tema.

Foram cinco as bibliotecas entrevistadas sendo, no total, entrevistados seis bibliotecários, um em cada biblioteca, exceto na Biblioteca Pública do Paraná, que a entrevista foi com dois profissionais pela amplitude de seus projetos. 
Realizou-se as seguintes perguntas:

1 Quais projetos culturais a biblioteca oferece para a comunidade?

2 Qual é a participação da comunidade nos projetos oferecidos?

3 Quando a biblioteca foi fundada?

4 Há quanto tempo os projetos e a mediação cultural acontecem?

5 Com que frequência são realizados os projetos?

Como são descritas as características de uma população, nesse caso as características dos bibliotecários, bibliotecas e interagentes na sociedade, a pesquisa é descritiva.

A pesquisa qualitativa não se preocupa com amostragens numéricas, mas sim com o aprofundamento da compreensão de um grupo social a fim de mostrar a realidade. Para Minayo (2001), a pesquisa qualitativa trabalha com o universo de significados, motivos, aspirações, crenças, valores e atitudes que corresponde a um espaço mais profundo das relações, dos processos e dos fenômenos que não podem ser reduzidos à operacionalização de variáveis. Por se tratar de uma pesquisa empírica, muitas vezes é criticada.

Foi utilizada a pesquisa bibliográfica para sustentar a argumentação teórica, segundo Gil (1991), esse tipo de pesquisa é elaborado a partir de material já publicado, constituído principalmente de livros, artigos de periódicos e atualmente com material disponibilizado na Internet. Para isso, buscaram-se argumentos e conceitos de pesquisadores que pudessem contribuir com o tema da mediação cultural e as ações promovidas por bibliotecas públicas, com vistas a introduzir a discussão e apresentação dos resultados.

\section{DISCUSSÃO E APRESENTAÇÃO DOS RESULTADOS}

Conforme descrito nos procedimentos metodológicos, nesta seção são apresentadas as informações organizadas, coletadas a partir das entrevistas com as/os bibliotecárias/os das instituições.

A Biblioteca Pública do Paraná (BPP), fundada em 1857, é um exemplo 
de biblioteca pública que atua prontamente na construção cultural, intelectual e social do indivíduo. A BPP tem uma agenda extensa de ações culturais voltadas para um diverso público alvo. Aqui nos cabe citar que, com agendamento prévio, a biblioteca realiza "Bibliotour" onde as escolas levam seus alunos para conhecer todos os setores da biblioteca, desde o acervo, processamento técnico, área de restauro entre outros. Essa ação aproxima as crianças do bibliotecário e das atividades que por ele são desempenhadas.

A BBP possui inúmeros projetos que ocorrem semanal ou mensalmente, entre eles podemos citar: Aventuras literárias, Aventuras teatrais, Biblioteca Paraná, Caixa Estante, Hora do Conto, Jornal Cândido, Música na Biblioteca, Oficina de Criação Literária, Oficina de llustração, Um escritor na biblioteca, Uma noite na biblioteca e o Prêmio Paraná de Literatura.

Além dos projetos, ocorrem ações sazonais, como o Piquenique Literário da Biblioteca que ocorre em alguma praça de Curitiba com contação de histórias, trocas de livros e grupos de estudos e o Cine Pipoca que além de passar o filme, ao final ocorre uma discussão a cerca do que foi assistido, ações que tornam o usuário parte da ação.

$\mathrm{Na}$ temporada de férias escolares, a BBP realiza uma programação ainda mais extensa, promovendo cinema, encontros de RPG e cards games, contação de lendas brasileiras, oficinas de artesanato entre outras. Essas ações comprovam a preocupação social da biblioteca pública com a comunidade e tornam a biblioteca um espaço ativo que cumpre o papel de auxílio na formação do indivíduo autônomo e construtor de sentido.

Na perspectiva do sujeito como produtor de sentidos, o leitor assume papel atuante. Deixa de ser mero decodificador ou receptor passivo, passando a ser construtor, coautor da informação ou do texto, como alerta Almeida Jr (2009).

No centro de Curitiba, no calçadão da rua XV, encontra-se o chamado Bondinho da Leitura que não se trata de uma biblioteca pública clássica. Ele foi revitalizado em 2010 e é um ponto turístico da cidade. Dentro do bondinho encontram-se mais de 3000 títulos que podem ser emprestados gratuitamente, apenas com a apresentação do documento de identificação. O Bondinho é um 
atrativo e torna-se bastante utilizado por estar localizado em uma área com bastante circulação de pedestres. Além de oferecer um lugar tranquilo para leitura em meio ao centro da cidade, o Bondinho realiza semanalmente contações de histórias no calçadão. A ação é bastante interessante pois, a mediação vai de encontro a comunidade em meio a sua rotina habitual. $A$ arte $e$ a literatura são expostas ao transeunte muitas vezes sem aviso prévio, sem limites de espaço.

No Bosque do Alemão, encontra-se a Biblioteca do Bosque do Alemão, ela foi inaugurada em 1996 e é uma biblioteca infantil. O lugar é muito atrativo para as crianças, pois, na trilha, que leva à biblioteca temática, estão expostos trechos do conto João e Maria, dos Irmãos Grimm. A biblioteca realiza semanalmente contação de histórias para a comunidade em geral, além de, com agendamento prévio, atender a escolas da região. As contações de histórias são realizadas por bruxas e ao final, as crianças podem abandonar sua chupeta na árvore das chupetas, para que a bruxa não vá assombrá-la.

Os Faróis do Saber em Praças são bibliotecas localizadas em praças de bairros de Curitiba, o primeiro, (ao todo são 9), foi inaugurado em 1994. A forma arquitetônica é referência ao farol de Alexandria. Todos os Faróis do Saber disponibilizam computadores com acesso gratuito à internet, medida bastante importante para inclusão digital. Além dos empréstimos, consulta local, os faróis do saber promovem a hora do conto, semanalmente e outros projetos, como teatro na biblioteca e palestras, sazonalmente. Os Faróis são importantes meios de atender aos bairros curitibanos, evitando que exista a necessidade do deslocamento dos interagentes para ter acesso a ações culturais e informação.

A Casa de Leitura Manoel Carlos Karam, localizada no parque Barigui possui espaço para leitura e disponibiliza diversos serviços culturais e literários como: oficinas de criação literária, sarais, rodas de leitura, laboratório de leitura e contação de histórias.

Deve-se ressaltar também que as cinco bibliotecas pesquisadas possuem ambiente bastante bonito e agradável para se permanecer, isso motiva e estimula o interagente a sair de casa e optar pela biblioteca ao invés de buscar outra forma de lazer. 
No quadro 1, é possível visualizar juntos os projetos realizados nas bibliotecas entrevistadas e suas respectivas descrições:

Quadro 1- Síntese dos projetos realizados nas bibliotecas entrevistadas

\begin{tabular}{|c|c|c|}
\hline Item & PROJETO & DESCRIÇÃO \\
\hline 01 & Bibliotour & $\begin{array}{l}\text { Passeio pela Biblioteca com o intuito de } \\
\text { apresentar aos usuários todos os setores da } \\
\text { biblioteca, como, por exemplo, a Divisão de } \\
\text { Preservação e a Seção Braille, que realizam } \\
\text { trabalhos que poucos leitores conhecem. }\end{array}$ \\
\hline 02 & Aventuras literárias & $\begin{array}{l}\text { Reúne autores para um bate-papo com o público } \\
\text { infanto-juvenil. Durante os encontros, os autores } \\
\text { conversam com os jovens leitores sobre suas } \\
\text { trajetórias na literatura e a importância da leitura } \\
\text { nas primeiras fases da vida. }\end{array}$ \\
\hline 03 & Aventuras teatrais & $\begin{array}{l}\text { Uma vez por mês é apresentada uma peça teatral } \\
\text { com a temática infantil. }\end{array}$ \\
\hline 04 & Biblioteca Paraná & $\begin{array}{l}\text { Realiza a publicação de livros de diversos } \\
\text { gêneros para suprir lacunas do meio editorial e } \\
\text { oferecer ao público uma dimensão da produção } \\
\text { literária estadual. }\end{array}$ \\
\hline 05 & Caixa Estante & $\begin{array}{l}\text { Tem por objetivo levar livros para empresas e } \\
\text { instituições a fim de incentivar a leitura em novos } \\
\text { espaços. A caixa é retirada na biblioteca e pode } \\
\text { permanecer na empresa por } 4 \text { meses. }\end{array}$ \\
\hline 06 & Hora do Conto & $\begin{array}{l}\text { O objetivo da "Hora do Conto" é contar histórias } \\
\text { de forma alegre e agradável, a fim de atrair as } \\
\text { crianças para o universo da literatura e, desta } \\
\text { maneira, ajudar na formação de novos leitores. } \\
\text { Cada história é adaptada e apresentada de forma } \\
\text { distinta, utilizando técnicas como fantoches e } \\
\text { sombras. Ocorre todos os dias em dois horários. }\end{array}$ \\
\hline 07 & Jornal Cândido & $\begin{array}{l}\text { Jornal literário de publicação mensal, com tiragem } \\
\text { de } 10 \text { mil exemplares, distribuído gratuitamente } \\
\text { na biblioteca, em escolas e centros culturais, a fim } \\
\text { de transformar a biblioteca num centro de difusão } \\
\text { de cultura. }\end{array}$ \\
\hline 08 & Música na Biblioteca & $\begin{array}{l}\text { Apresentação de música todas as sextas-feiras } \\
\text { que contempla diversos gêneros musicais, } \\
\text { incentiva e dá visibilidade a músicos e } \\
\text { compositores locais. }\end{array}$ \\
\hline 09 & $\begin{array}{l}\text { Oficina de Criação } \\
\text { Literária }\end{array}$ & $\begin{array}{l}\text { Cursos mensais que buscam aliar teoria e prática } \\
\text { à experiência dos convidados, colocando o } \\
\text { público em contato com diversos gêneros sob a } \\
\text { perspectiva dos principais autores da literatura } \\
\text { brasileira contemporânea. }\end{array}$ \\
\hline
\end{tabular}




\begin{tabular}{|c|c|c|}
\hline Item & PROJETO & DESCRICÃO \\
\hline 10 & Oficina de Ilustração & $\begin{array}{l}\text { Tem o objetivo de estimular artistas iniciantes e } \\
\text { aprimorar as técnicas de quem já atua no } \\
\text { mercado, os participantes aliam teoria e prática } \\
\text { das artes gráficas e têm contato com cartunistas } \\
\text { e quadrinistas reconhecidos nacionalmente. } \\
\text { Ocorrem semestralmente. }\end{array}$ \\
\hline 11 & $\begin{array}{l}\text { Um escritor } \\
\text { biblioteca }\end{array}$ & $\begin{array}{l}\text { Bate-papos com autores da literatura brasileira } \\
\text { contemporânea sobre suas carreiras e obras. } \\
\text { Sempre com a presença de um mediador, os } \\
\text { escritores são instigados a falar sobre temas } \\
\text { variados, como processo criativo, hábitos de } \\
\text { leitura, livros essenciais, etc. A primeira pergunta } \\
\text { é sempre sobre a relação do convidado com as } \\
\text { bibliotecas. Ocorre mensalmente desde } 1980 \text {. }\end{array}$ \\
\hline 12 & $\underset{\text { biblioteca }}{\text { Uma noite }}$ & $\begin{array}{l}\text { A iniciativa oferece ao público infantil uma série } \\
\text { de atividades gratuitas relacionadas ao universo } \\
\text { da leitura. A programação tem início no final da } \\
\text { tarde e segue durante a noite e madrugada com } \\
\text { dança, música, contação de histórias, teatro, } \\
\text { oficinas e gincanas. Os participantes dormem na } \\
\text { Biblioteca e o evento termina na manhã do dia } \\
\text { seguinte com um café da manhã. }\end{array}$ \\
\hline 13 & $\begin{array}{l}\text { Prêmio Paraná de } \\
\text { Literatura }\end{array}$ & $\begin{array}{l}\text { Concurso literário com objetivo de homenagear a } \\
\text { literatura local. }\end{array}$ \\
\hline 14 & Piquenique Literário & $\begin{array}{l}\text { Realizado sazonalmente em alguma praça de } \\
\text { Curitiba com contação de histórias, trocas de } \\
\text { livros, rodas de leitura e trocas de conhecimentos. }\end{array}$ \\
\hline 15 & Cine Pipoca & $\begin{array}{l}\text { Mostra de filme com discussão sobre o filme após } \\
\text { a sessão. Ocorre sazonalmente. }\end{array}$ \\
\hline 16 & $\begin{array}{l}\text { Encontros de RPG e } \\
\text { cards games }\end{array}$ & $\begin{array}{l}\text { Encontros realizados nos períodos de férias } \\
\text { escolares para promover a interação entre os } \\
\text { usuários. }\end{array}$ \\
\hline 17 & $\begin{array}{l}\text { Contação de lendas } \\
\text { brasileiras }\end{array}$ & $\begin{array}{l}\text { Busca aproximar os participantes do folclore } \\
\text { nacional por meio de técnicas do teatro de } \\
\text { sombras e de fantoches. Ocorre nos períodos de } \\
\text { férias. }\end{array}$ \\
\hline 18 & Oficinas de artesanato & $\begin{array}{l}\text { Ensina crianças a criarem seus próprios } \\
\text { brinquedos e objetos. Ocorre sazonalmente. }\end{array}$ \\
\hline 19 & $\begin{array}{l}\text { Contações de histórias } \\
\text { no calçadão }\end{array}$ & $\begin{array}{l}\text { Mediação a fim de levar literatura e arte para as } \\
\text { ruas. Ocorre semanalmente. }\end{array}$ \\
\hline
\end{tabular}




\begin{tabular}{|c|c|c|}
\hline Item & PROJETO & DESCRIÇÃO \\
\hline 20 & Árvore das chupetas & $\begin{array}{l}\text { Utilizada estimular a criança a abandonar a } \\
\text { chupeta após a contação de história. }\end{array}$ \\
\hline 21 & Teatro na biblioteca & $\begin{array}{l}\text { Apresentação de peças com temáticas variadas } \\
\text { com objetivo de promover acesso à cultura, } \\
\text { estimular a reflexão e valorizar os artistas locais. }\end{array}$ \\
\hline 22 & Palestras & $\begin{array}{l}\text { Para suprir necessidades informacionais da } \\
\text { comunidade. }\end{array}$ \\
\hline 23 & $\begin{array}{l}\text { Computadores com } \\
\text { acesso gratuito à } \\
\text { internet }\end{array}$ & $\begin{array}{l}\text { Medida de inclusão digital e disseminação de } \\
\text { informação. }\end{array}$ \\
\hline 24 & Sarais & $\begin{array}{l}\text { Recitação de poesias, peças teatrais, música com } \\
\text { objetivo de proporcionar o acesso a diversas } \\
\text { manifestações artísticas e interação social. }\end{array}$ \\
\hline 25 & Rodas de leitura & $\begin{array}{l}\text { Leituras acompanhadas a fim de promover troca } \\
\text { de conhecimentos. }\end{array}$ \\
\hline 26 & Laboratório de leitura & $\begin{array}{l}\text { Auxílio na interpretação de textos literários para } \\
\text { aproximar o leitor de novas linguagens. }\end{array}$ \\
\hline 27 & Revista Helena & $\begin{array}{l}\text { Publicada trimestralmente, cada edição um tema } \\
\text { conduz o leitor ao conteúdo que mostra um pouco } \\
\text { da atividade cultural paranaense, a partir do olhar } \\
\text { atento de colaboradores que conhecem a fundo } \\
\text { nossas histórias. }\end{array}$ \\
\hline 28 & $\begin{array}{l}\text { Divulgação dos livros } \\
\text { mais emprestados }\end{array}$ & $\begin{array}{l}\text { Serve como estímulo e sugestão de leitura para } \\
\text { os interagentes. Divulgação mensal. }\end{array}$ \\
\hline
\end{tabular}

Fonte: Dados da Pesquisa, 2019.

Verifica-se por intermédio desses 28 projetos listados, que as bibliotecas mencionadas estão atentas às necessidades locais. Todos os projetos realizados nas bibliotecas entrevistadas possuem participação ativa da comunidade, sendo assim, pode-se afirmar que as ações culturais são um atrativo aos interagentes e que, a biblioteca, quando busca novos caminhos no desempenho de suas funções, possui espaço e poder na construção social. 


\section{CONSIDERAÇÕES FINAIS}

Conforme discutido, é pertinente que a biblioteca proporcione ações culturais e mediações que sejam atrativas para as necessidades da comunidade em que está inserida. Dessa forma, torna-se relevante desenvolver atividades para funcionar como um lugar de cultura e formação de cidadãos pensantes, que assumam papéis sociais e façam uso adequado do conhecimento. As bibliotecas públicas analisadas na pesquisa mostram-se ativas, bem frequentadas pela comunidade, e com um importante papel social e por sua visibilidade integradora.

Assim, entende-se que o objetivo da pesquisa de descrever práticas culturais a fim de conhecer a dinâmica das bibliotecas públicas de Curitiba se concretizou, pois, obteve-se o detalhamento de 28 projetos culturais que acontecem com participação da comunidade. Dessa forma, este artigo pode contribuir com outras unidades de informação, servindo como inspiração para um atuar bibliotecário que supra as necessidades locais da comunidade em que estão inseridos.

Como afirma Brayner (2018, p. 21) o profissional da Biblioteconomia deve "coadunar a nossa linguagem ao modo de expressão pública para assim podermos traçar um verdadeiro diálogo com aqueles que buscam os nossos serviços".

Verifica-se que no decorrer do trabalho esteve evidenciado como bibliotecárias e bibliotecários podem auxiliar no desenvolvimento da comunidade e como a mediação cultural pode gerar inclusão, apropriação da informação, desenvolver estímulos para novas áreas de conhecimento, promover lazer, entretenimento e acesso à cultura.

Por fim, compreende-se que a pesquisa deve ser continua, pois, em face às inovações tecnológicas e novas vivências, a atuação da biblioteca necessita por meio de seus profissionais estar atenta às necessidades econômicas, políticas, culturais e sociais de seus interagentes.

\section{REFERÊNCIAS}


ALMEIDA, Marco Antônio de. Informações e mediações: considerações em torno de Latour e Becker. In: SANTARÉM SEGUNDO, José Eduardo; MOSTAFA, Solange Puntel; SILVA, Márcia Regina da (org.) Os pensadores e a Ciência da Informação. Rio de Janeiro: E-papers, 2012.

BIBLIOTECA PÚBLICA DO PARANÁ. Disponível em: http://www.bpp.pr.gov.br/.

BRAYNER, Cristian. A biblioteca de Foucalt: reflexões sobre ética, poder e informação. São Paulo: É Realizações, 2018.

COSTA, Karine. A biblioteca pública entre o ser e o ter. In: PRADO, Jorge do. (org.). Ideias emergentes em biblioteconomia. São Paulo: FEBAB, 2016.

CUNHA, Vanda Angélica. Profissional da informação na biblioteca pública contemporânea: o bibliotecário e a demanda por educação continuada. 2002. 191f. Dissertação (Mestrado em Ciência da Informação) - Universidade Federal da Bahia - Instituto de Ciência da Informação. Salvador, 2002.

DANTAS, José Guibson Delgado. Teoria das mediações culturais: uma proposta de Jesús Martín- Barbero para o estudo da recepção. In: CONGRESSO DE CIÊNCIAS DA COMUNICAÇÃO NA REGIÃO NORDESTE, 10, 2008, São Luís. Anais [...] São Luís :Intercom- Sociedade Brasileira de Estudos Interdisciplinares da Comunicação, 2008. Disponível em: http://www.intercom.org.br/papers/regionais/nordeste2008/resumos/R12-00151.pdf.

GIL, Antonio Carlos. Como elaborar projetos de pesquisa. São Paulo: Editora Atlas, 2010.

GIL, Antônio Carlos. Como elaborar projetos de pesquisa. 3. ed. São Paulo: Atlas, 1991.

GIL, Antonio Carlos. Métodos e técnicas de pesquisa social. 6. ed. São Paulo: Atlas, 2008.

LOPES, Jorge (org.). 0 fazer do trabalho científico em ciências sociais aplicadas. Recife: Ed. Universitária do UFPE, 2006.

MALHOTRA, Naresh K. Pesquisa de marketing. 3. ed. Porto Alegre: Bookman, 2001.

MARTINS, Mirian Celeste; PICOSQUE, Gisa. Mediação cultural para professores andarilhos na cultura. São Paulo: Intermeios, 2012.

MINAYO, Maria Cecília de Souza (org.). Pesquisa social: teoria, método e criatividade. Petrópolis: Vozes, 2001.

RASTELI, Alessandro; CAVALCANTE, Lídia Eugênia. Mediação cultural e apropriação da informação em bibliotecas públicas. Encontros Bibli: revista 
eletrônica de biblioteconomia e ciência da informação, v. 19, n. 39, p. 43-58, jan./abr., 2014. Disponível em:

https://periodicos.ufsc.br/index.php/eb/article/view/1518-2924.2014v19n39p43.

ROESCH, Sylvia Maria Azevedo. Projetos de estágio e de pesquisa em

Administração: guia para estágios, trabalho de conclusão, dissertações e outros estudos de caso. 2. ed. São Paulo: Atlas, 1999.

SANCHES, Gisele A. Ribeiro; RIO, Sinomar Ferreira do. Mediação da informação no fazer bibliotecário e seu processo em bibliotecas universitárias no âmbito das ações culturais. InCID: Revista de Ciência da Informação e Documentação. Ribeirão Preto. v. 1. n. 2. p. 103-121. Jul./dez. 2010. Disponível em: http://ww.periodicos.usp.br/incid/article/view/42323.

Silveira, Fabrício José Nascimento da; REIS, Alcenir Soares dos. Biblioteca como lugar de práticas culturais: uma discussão a partir dos currículos de Biblioteconomia no Brasil. São Paulo. 2008.

TRIVIÑOS, Augusto Nibaldo Silva. Introdução à pesquisa em ciências sociais: a pesquisa qualitativa em educação. São Paulo: Atlas, 1987.

\title{
CULTURAL MEDIATION IN CURITIBA PUBLIC LIBRARIES
}

\begin{abstract}
Introduction: When considering the role of public libraries as essential to collaborate with the dissemination and visibility of different cultural manifestations and their contribution to the dissemination and consolidation of knowledge, the presented research brings an analysis of the current situation of public libraries and their professionals in the city of Curitiba. Objective: In order, to describe cultural practices and understand the dynamics of public libraries in Curitiba. Methodology: To this end, exploratory, bibliographic, descriptive, and qualitative research was carried out. Results: It was obtained the identification and description of 28 projects that can be characterized as cultural practices. Conclusions: It is evident that librarians and librarians can assist in community development and cultural mediation can generate inclusion, appropriation of information, develop incentives for new areas of knowledge, promote leisure, entertainment, and access to culture.
\end{abstract}

Descriptors: Cultural mediation. Public Library. Librarian. Librarianship.

\section{MEDIACIÓN CULTURAL EN LAS BIBLIOTECAS PÚBLICAS DE CURITIBA}

\section{RESUMEN}

Introducción: Considerando el papel fundamental de las bibliotecas públicas en la colaboración con la difusión y la visibilidad de las diversas manifestaciones culturales y 
su contribución a la difusión y consolidación del conocimiento, la investigación presentada aporta un análisis de la situación actual de las bibliotecas públicas y sus profesionales en la ciudad de Curitiba. Objetivo: Describir las prácticas culturales y conocer la dinámica de las bibliotecas públicas de Curitiba. Metodología: Con este fin, se realizó una investigación exploratoria, bibliográfica, descriptiva y de enfoque cualitativo. Resultados: Identificación y descripción de 28 proyectos que pueden caracterizarse como prácticas culturales. Conclusiones: Es evidente que los bibliotecarios pueden ayudar en el desarrollo de la comunidad y la mediación cultural puede generar inclusión, apropiación de la información, desarrollar estímulos para nuevas áreas del conocimiento, promover el ocio, el entretenimiento y el acceso a la cultura.

Descriptores: Mediación cultural. Biblioteca pública. Bibliotecario. Biblioteconomía.

Recebido em: 11.08 .2020

Aceito em: 18.11 .2020 